\title{
SNOW FLIES AND OTHER WINTER INVERTEBRATES NEAR PINAWA, MANITOBA
}

Peter Taylor

P.O. Box 597, Pinawa, MB ROE 1 L0

taylorp@granite.mb.ca

Snow flies (Diptera: Tipulidae: Chionea) are small, flightless crane flies with the surprising habit of walking considerable distances (tens of metres, possibly farther) during winter on snow in forested areas at temperatures near the freezing point (Figs. 1 to 3). ${ }^{1-3}$ Having seen them a few times near Pinawa, Manitoba, I conducted surveys between 2009 and 2015 to define their seasonal occurrence and estimate their density on the snow surface, while also noting any other invertebrate activity.

All the snow flies observed were assumed to be C. valga, the widestranging North American Chionea species, which occurs from Alberta to Labrador and southward to Minnesota and Virginia. ${ }^{1,3}$ Individuals were not examined microscopically, but some photographs show just enough detail to support this identification (Figs. 1 to 3).2,4 Byers' distribution map for C. valga includes two Alberta and three Manitoba localities, but none in Saskatchewan. It is reasonable to expect this species to occur across the boreal forest in the three Prairie provinces. One of the reported Manitoba localities is Red Rock Lake, $30 \mathrm{~km}$ southeast of Pinawa. ${ }^{1}$ There is also one recent report of an eastern species, C. scita, in Manitoba. ${ }^{5}$

The sex of individual snow flies is easily determined by the shape of the abdominal appendages: upward-curving and finely tapered in females (Fig. 2), blunt and pincer-like in males (Fig. 3) ${ }^{1,4}$ Specimens of $C$ valga vary considerably in size: Byers gives body-length ranges (excluding antennae) of 3.5 to $6.0 \mathrm{~mm}$ for males and 4 to $8 \mathrm{~mm}$ for females. In a normal walking posture, the span of the legs is three or four times the body length (Figs. 2 and 3) Large males have robust proportions (especially the legs), while small males are relatively slender. ${ }^{1}$

\section{Study Area and Survey Procedure}

The 1.5-km survey route, centred just north of Pinawa at $50.166^{\circ} \mathrm{N}$, $95.864^{\circ} \mathrm{W}$, follows a lightly used, single-track snowmobile trail in second-growth, mixed-wood forest (Fig. 4), primarily trembling aspen (Populus tremuloides) and balsam fir (Abies balsamea) with some white birch (Betula papyrifera), balsam poplar (Populus balsamifera) and white spruce (Picea glauca). Slightly lower-lying areas have black spruce (Picea mariana), tamarack (Larix laricina), black ash (Fraxinus nigra), and some treeless marsh, while bur

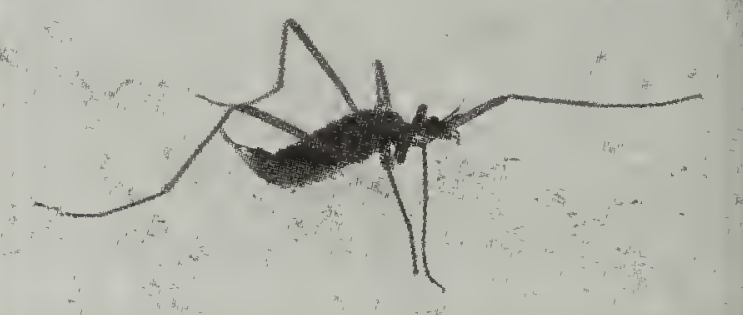

Figure 2. Chionea valga female walking near Pinawa, January 27, 2015, viewed from the side, showing the finely tapered tip of the abdomen.

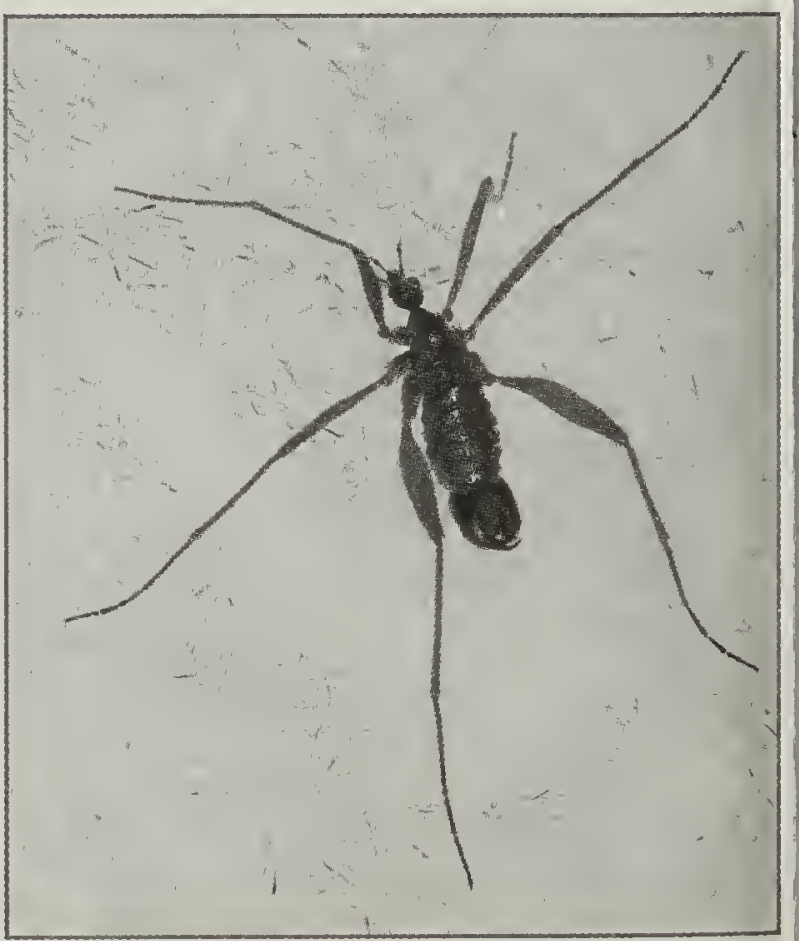

Figure 3. Chionea valga male near Pinawa, January 16, 2010, viewed from above, showing the pincer-like abdominal appendages. 


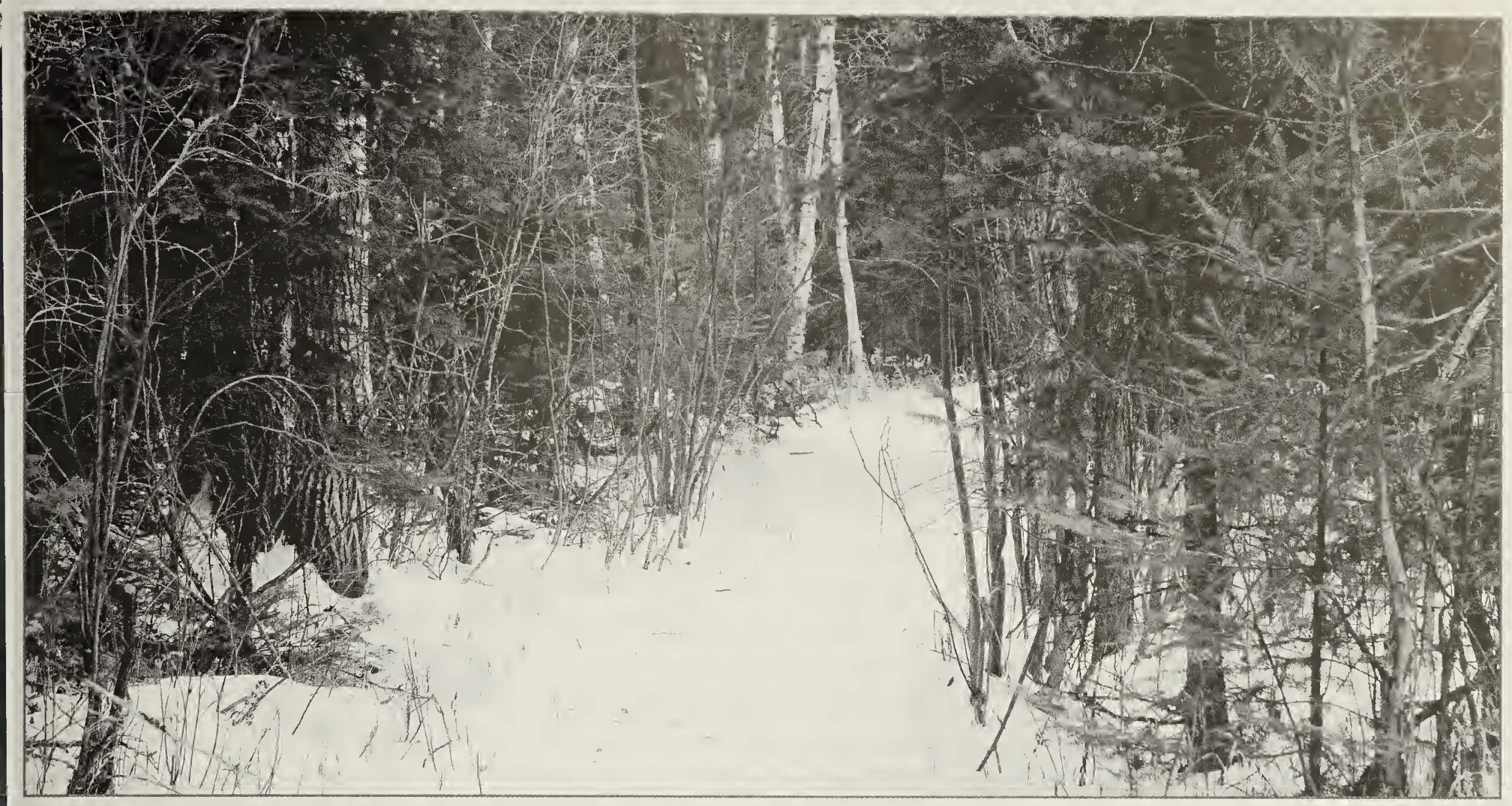

Figure 4. Mixed-wood forest habitat for snow flies near Pinawa

oak (Quercus macrocarpa) and jack pine (Pinus banksiana) are present in slightly elevated, rocky areas. The area has not been disturbed by major fires or logging for at least 60 years. Forest succession has proceeded to the point that many fir trees have reached the height of the aspen canopy (about $15 \mathrm{~m}$ ).

The route was surveyed by walking slowly in both directions and visually scanning the snow surface for invertebrates over an average width of about $3 \mathrm{~m}$ centred on the trail. Counting the outward and return journeys separately (given the mobility of C valga; see Discussion below), the area surveyed was equivalent to $9,000 \mathrm{~m}^{2}$ (0.9 ha) per round trip.

Extreme survey dates were November 23 (2014) and April 3 (2014). The number of surveys varied from year to year, with more than half in the 2014-2015 winter, but overall monthly coverage from December to March was fairly uniform (Table 1). Surveys were usually conducted in the afternoon (average start and finish times, 14:43 $\mathrm{h}$ and 16:07 $\mathrm{h}$ Central Standard Time), and the average round-trip duration was 1.4 hours. Weather conditions were usually overcast with light wind and no precipitation. Other reports indicate that the combination of timing and conditions was appropriate for finding snow flies. ${ }^{1-4,6,7}$ Detection of small invertebrates was impeded to varying degrees by fir needles and fine detritus on the snow surface. Overall, this probably did not affect detection of snow flies very much, but was more problematic with smaller, less mobile species such as snow fleas and rove beetles (see below)

The maximum temperatures on survey days, and minimum temperatures the previous night, as recorded at a weather station $14 \mathrm{~km}$ west of the study area, were obtained from the Environment Canada website (www. climate.weather. gc.ca). Shade temperatures measured in Pinawa before or after the surveys were normally within 2 degrees Celsius of these maxima. These temperatures represent prevailing conditions as opposed to the actual surface temperatures experienced by the observed invertebrates. In the deep shade along most of the trail, with little or no wind, the surface temperature is expected to be close to the air temperature when below $O C$, and close to $O C$ (controlled by thawing snow) when the prevailing air temperature is a few degrees higher

\section{Survey Results}

Invertebrate activity was detected on 20 of 22 surveys (90 per cent) with prevailing air temperatures between -6 and $+14 C$ (median, $+2 \mathrm{C})$, and with minima between -13 and $0 \mathrm{C}$ (median, $-7 \mathrm{C}$ ) on the nights preceding the surveys (Fig. 5). These temperatures are well above long-term seasonal averages for the December - February period of about -20 C (daily minimum) and $-10 \mathrm{C}$ (daily maximum). Three additional surveys, where no invertebrate activity was detected, followed cold nights (minima below - $20 \mathrm{C}$; three outlying points in Fig. 5). It is likely 


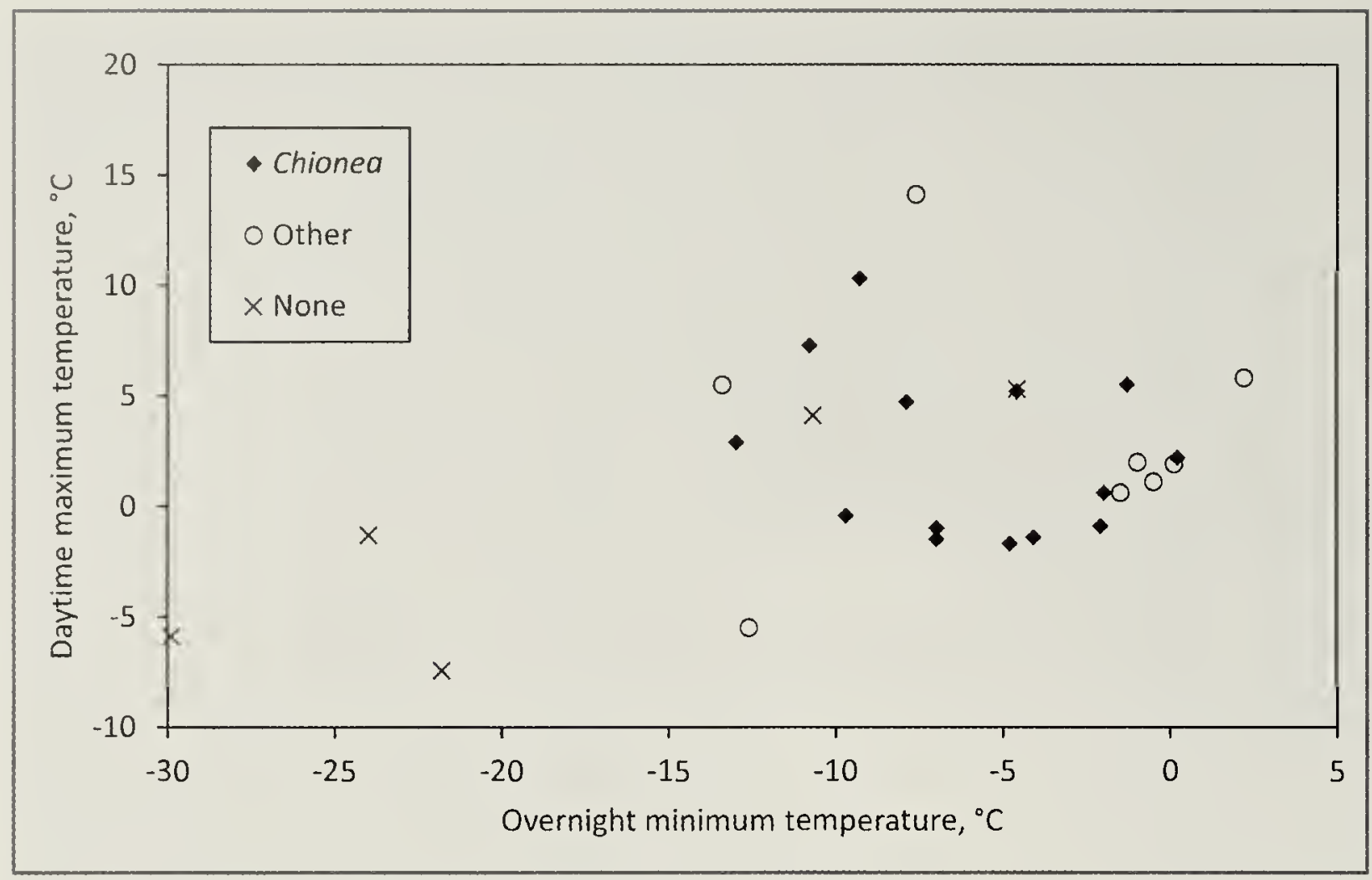

Figure 5:. Prevailing temperatures for 25 invertebrate survey days, and for two other days when snow flies were observed. The three symbols indicate whether Chionea valga and sometimes other invertebrates, other invertebrates but not C. valga, or no invertebrates were found

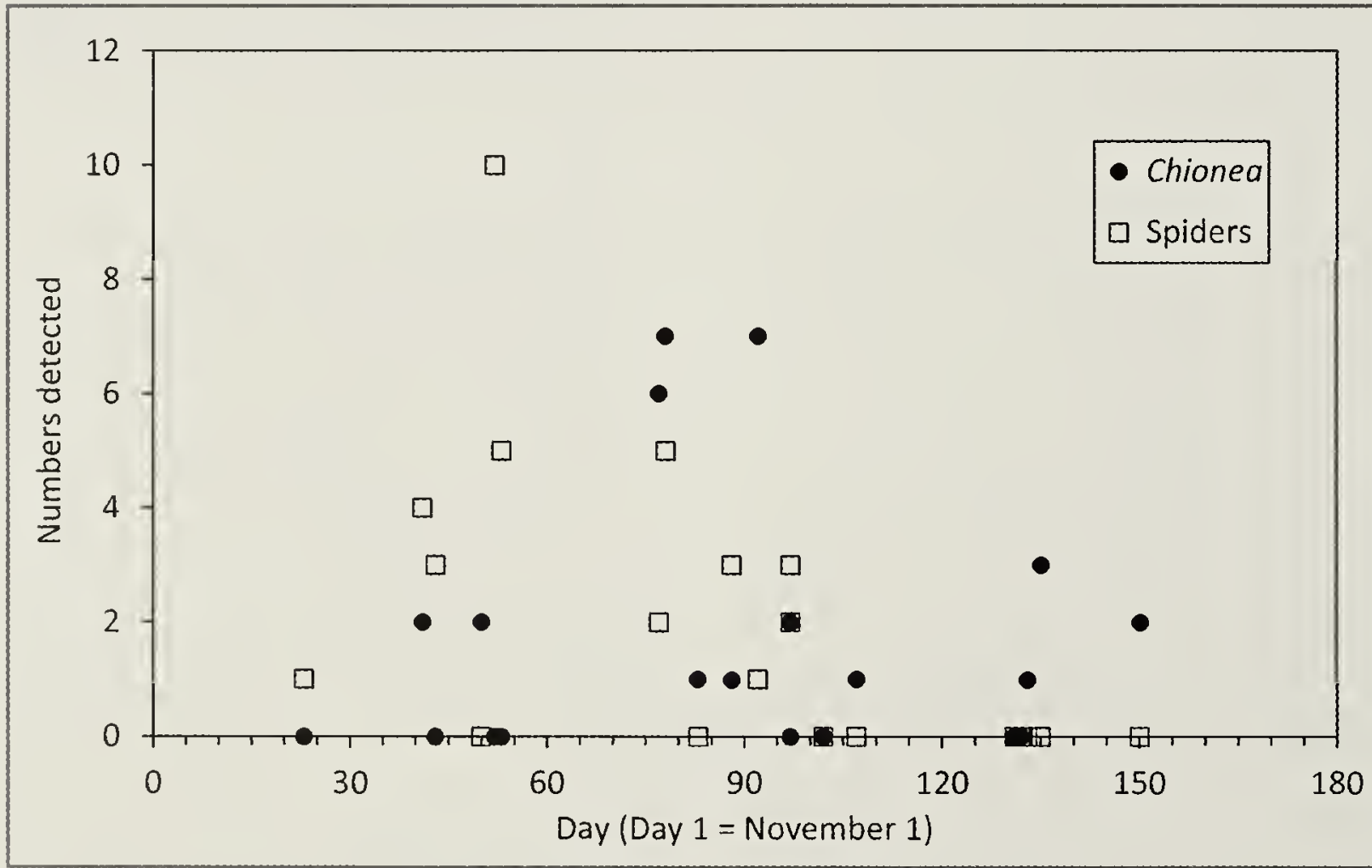

Figure 6. Numbers of snow flies (Chionea valga) and spiders (various species) detected on individual surveys.

that the low overnight temperatures, and correspondingly brief daytime mild conditions, inhibited invertebrate activity. Therefore these three surveys are included in Table 1 and Fig. 5, but were excluded from calculation of the following percentages, which are thus based on 22 surveys.

Altogether, 34 snow flies were detected on 12 surveys ( 55 per cent) in five different winters between December 11 (2014) and March 30 (2014), at prevailing temperatures between -2 and $+10 C$, as shown in Figs. 5 and 6. These comprised nine males, 17 females, and nine of undetermined sex (in some early surveys). High counts of six or seven were detected in the second half of January in three different years (January 16, 2010, January 17, 2015, and January 31, 2009); the remaining counts did not exceed three individuals. Incidental observations of single C. valga at other localities in the Pinawa area, November 18 and December 1, 2012, extend the observed activity period to November 18 - March 30.

Thirty-nine spiders (order Araneae; mostly unidentified, but evidently several species) were detected on 11 surveys (50 per cent) in five different winters. Extreme dates were November 23 (2014) and February 5 (2012), and the maximum count was 10 on December 22, 2014 (Fig. 6). Springtails or "snow fleas" (order Collembola, likely Hypogastrura nivicola) were detected in varying abundance on nine surveys (41 per cent) in four different winters between December 22 (2014) and March 13 (2014). These minute (about $2 \mathrm{~mm}$ total length), swarming creatures are perhaps the bestknown of all snow invertebrates. ${ }^{8-10}$ Dark-winged fungus gnats (Diptera: Sciaridae, at least two species) were detected on 10 surveys (45 per cent) in four different winters between November 23 (2014) and March 13 (2014). These tiny, fully winged insects were seen both flying and crawling on the snow (Fig. 7). It is doubtful that adults survive beyond the end of a mild spell; three live individuals and a dead one were noted on March 13, 2014, while at least five dead ones were seen under colder conditions three days later.

Two snow scorpion-flies (Mecoptera: Boreus sp.) were found but unfortunately not photographed on February 15, 2011. Several additional invertebrates were detected only once or twice in December (Figs. 8 and 9): tiny rove beetles (Coleoptera: Staphylinidae), a flightless gall wasp (Hymenoptera: Cynipidae, Philonix fulvicollis), a few small, unidentified flies or wasps, and an unidentified centipede (class (hilopoda).

Human traffic on the trail was very light. In 35 hours of surveys, I encountered only one snowmobile and (in 2015) three cross-country skiers. Snow compaction was just sufficient for easy walking. 
Table 1. Monthly and seasonal distribution of survey dates.

\begin{tabular}{|rrrrrrrr|r|}
\hline SEASON & NOV & DEC & JAN & FEB & MAR & APR & TOTAL \\
\hline $2008-2009$ & 0 & 0 & 1 & 0 & 1 & 0 & 2 \\
$2009-2010$ & 0 & 0 & 1 & 0 & 0 & 0 & 1 \\
$2010-2011$ & 0 & 0 & 0 & 2 & 0 & 0 & 2 \\
$2011-2012$ & 0 & 0 & $(1)^{*}$ & 1 & 1 & 0 & $2(1)$ \\
$2012-2013$ & 0 & 0 & 0 & 0 & 0 & 0 & 0 \\
$2013-2014$ & 0 & 0 & 0 & 0 & $2(2)$ & $(1)$ & $2(3)$ \\
$2014-2015$ & 1 & 5 & 3 & 1 & $1(1)$ & 0 & $11(1)$ \\
\hline TOTALS & 1 & 5 & $5(1)$ & 4 & $5(3)$ & $0(1)$ & $20(5)$ \\
\hline
\end{tabular}

* Numbers of surveys in which no invertebrates were detected are shown in parentheses

\section{Discussion}

Terrestrial invertebrate activity during winter in Manitoba is of course greatly reduced from summer levels, and largely restricted to locations beneath deep snow (subnivean habitat), where stable near-freezing temperatures occur. ${ }^{8,11}$ Activity on the snow surface (supranivean habitat), where temperatures often fall far below freezing, is much more limited.

The low numbers of $C$. valga detected in the surveys limit the data analysis, but some comparison is possible with studies of $C$. araneoides by Hågvar near Oslo, Norway. 2,12
The long activity period (November 18 - March 30, representing almost the entire period of lasting snow cover) is consistent with Hågvar's observations. ${ }^{12}$ It also supports Byers' inference, from a large compilation of specimen records, that $C$. valga has a single generation per year with long but undetermined individual life spans. ${ }^{1}$ Byers' compiled specimen records for C. valga extend from mid-September to early May, with the majority from December to March.

The three highest survey counts correspond to an apparent peak density of seven active snow flies per hectare of snow surface, and the remaining counts suggest an average season-long density of just one or two per hectare on suitable days. These values are much lower than densities of up to 86 C. araneoides per hectare obtained in Norway by Hågvar, using a similar single-transect methodology.

Apparent densities are subject to possible biases, both positive and negative. Funneling or trapping of insects along the trail would introduce a positive bias, i.e. higher density than the habitat average Individual C. valga crossed the survey trail with little difficulty, however, easily scaling short climbs at the rim of the trail, and being only briefly disoriented in trampled snow.

Thus, snow flies seemed neither to avoid the trail nor to be hindered or delayed much by it. If snow flies

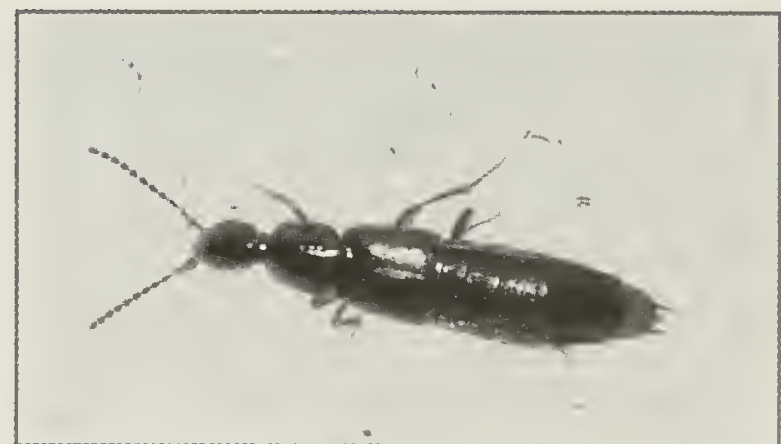

Figure 8 Rove beetle (Coleoptera: Staphylinidae) near Pinawa, December 23, 2014.

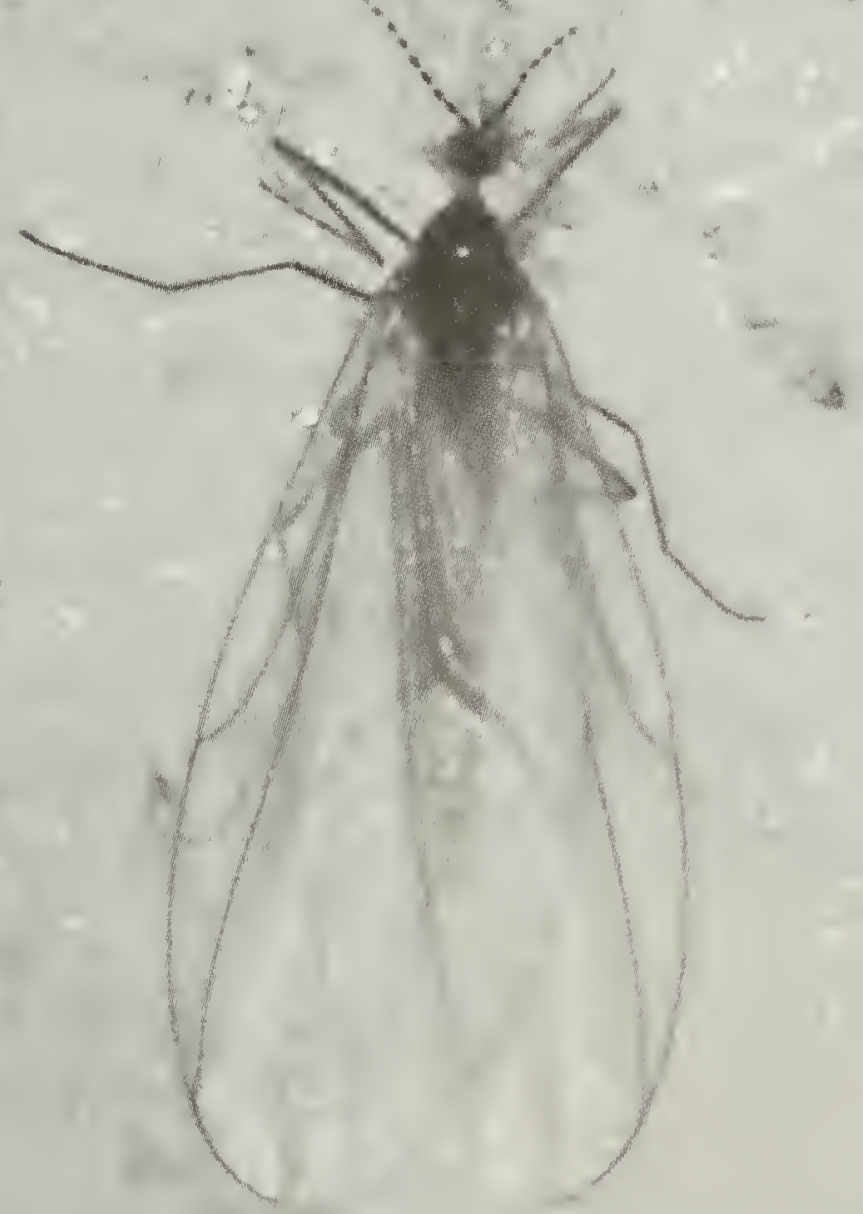


avoided the compacted snow along

the trail, this would introduce a negative bias; however, frequent binocular scans off-trail failed to reveal any additional insects. Based on these observations I suspect, if anything, a slight positive bias to the apparent densities, and believe that comparison with Hågvar's numbers is valid. Possibly the second-growth forest sampled in the Pinawa surveys is not optimal habitat for C. valga. Paquin indicates that, in Quebec, C. valga is associated mainly with mature and old-growth forest. ${ }^{13}$

The observed densities represent only those individual insects that emerge from beneath the snow to roam on the surface, and are not indicative of actual population densities. Byers interpreted surface movements as a means of dispersal to assure genetic diversity, rather than a mate-location strategy as previously suggested. ${ }^{1-3,7}$ Such dispersal may only involve a small fraction of the population. The late-January cluster of high survey counts for C. valga (Fig. 6) is statistically significant, based on calculated Poisson distributions for 34 random encounters on 22 surveys at constant density. This cluster coincides with a January activity peak for $C$. araneoides, which corresponds with peak egg-laying in that species in Norway. 2,12

The only localized concentration observed was a group of three (from a survey total of six) within about $3 \mathrm{~m}$ of each other on January 16 , 2010. The overall count of nine males and 17 females is not a significant deviation from a $1: 1$ sex ratio at the 95 per cent confidence level (based on binomial distribution). For $C$. araneoides in Norway, Hågvar found a sex ratio close to 1:1 with much larger samples (daily totals as high as 50 males and 43 females). ${ }^{2}$

The temperatures shown in Fig. 5 indicate the range of suitable prevailing conditions for seeking C. valga. There is insufficient data under marginal conditions to define upper and lower limits for activity, but several previous authors have investigated this in detail. Hågvar found $C$. araneoides in chill coma (i.e. immobile) in the field at -5 to -6 C.2 Aitchison compiled minimum activity temperatures ranging from -10 to -2 C, as reported by various authors for other Chionea species. ${ }^{8}$

While spiders slightly outnumbered snow flies in the survey totals, they were found primarily in December and January, with none later than February 5 (2011). Compared with snow flies their movements on the snow surface were slow and limited, as noted previously by Chapman. ${ }^{6}$ Aitchison found that many Manitoba spider species are relatively coldhardy, remaining active well into the winter, but none appear to be winter specialists like snow flies. ${ }^{11}$

\section{Further Reading}

The biogeography and evolutionary history of the 35 Chionea species currently recognized worldwide have been discussed by de Jong and Ciliberti. ${ }^{14}$ These insects occur in boreal and montane forested regions of Eurasia and North America with lasting winter snow cover. The taxonomy, anatomy, physiological adaptation for low-temperature activity, and natural history of North American species has been reviewed in detail by Byers, as summarized by Schrock. 1,3 Aitchison has reviewed winter invertebrate activity worldwide, with emphasis on activity in subnivean habitats where a stable microclimate exists. ${ }^{8}$ Internet searching reveals many other publications, from old anecdotal reports of snow flies to recent papers on newly described species from southern Europe to China and Korea. I would be interested to hear of other observations of C. valga in or near the Prairie Provinces.

I thank Scott Digweed for the wasp identification and Terry Galloway for helpful information.

1. Byers GW (1980) The crane fly genus Chionea in North America, The University of Kansas Science Bulletin 52:59-195.

2. Hågvar S (1971) Field observations on the ecology of a snow insect, Chionea araneoides Dalm. (Dipt., Tipulidae), Norsk Entomologisk Tidsskrift (Norwegian Journal of Entomology) :33-37.

3. Schrock JR (1992) Snow flies, The Kansas School Naturalist, 38(2):3-16; available online at www.emporia.edu/ksn/.

4. Johnson CW (1907) The snow-fly, Chionea valga Harris, Psyche 14:41-43.

5. Burrows, BL (2010) Two reasons not to eat snow, Nature Manitoba News 2(1):5.

6. Chapman JW (1954) Observations on snow insects in western Montana, The Canadian Entomologist 86:357-363.

7. Marchand W (1917) Notes on the habits of the snow-fly (Chionea), Psyche 24:142-152.

8. Aitchison CW (2001) The effect of snow cover on small animals, Chapter 5 (pp. 229-265) in: Jones HG, Pomeroy J, Walker DA, Hohan R (editors), Snow Ecology, Cambridge University Press.

9. Smith AR, Lahey AL (1984) Of ice worms and snow fleas, Blue Jay 42:24-25.

10. Christiansen K (1993) Springtails, The Kansas Schoo/ Naturalist, 39(1):3-16; available online at www.emporia.edu/ksn/.

11. Aitchison CW (1976) The activity of subnivean invertebrates in southern Manitoba, M. Sc. Thesis, University of Manitoba, Winnipeg MB.

12. Hågvar S (1976) Phenology of egg development and egg-laying in a winteractive insect, Chionea araneoides Dalm. (Dipt., Tipulidae), Norwegian Journal of Entomology 23, 33-37.

13. Paquin $P$ (2001) Huit espèces d'insectes associées aux forêts matures et anciennes (Eight insect species associated with mature and ancient forests), Le Naturaliste Canadien 125:115-121.

14. De Jong H, Ciliberti $P$ (2014) How coldadapted flightless flies dispersed over the northern hemisphere: phylogeny and biogeography of the snow fly genus Chionea Dalman (Diptera: Limoniidae), Systematic Entomology 39, 563-589. 